\title{
PHARMACOKINETIC STUDY OF MATRIX MEMBRANE MODERATED TRANSDERMAL SYSTEM OF BOSENTAN MONOHYDRATE
}

\author{
REVATHI MANNAM, INDIRA MUZIB YALLAMALLI*
}

Department of Pharmaceutics, Institute of Pharmaceutical Technology, Sri Padmavati Mahila Visvavidyalaym (Women's University), Tirupati, Andhra Pradesh, India. Email: yindira1415@gmail.com

Received: 19 April 2017, Revised and Accepted: 30 May 2017

\section{ABSTRACT}

Objective: The objective of the present research work is to carry out the pharmacokinetic studies of optimized matrix membrane moderated transdermal patch of bosentan monohydrate.

Materials and Methods: The matrix membrane moderated transdermal system was formulated using HPMC, HPMC K4M and E RLPO. In vitro diffusion studies were carried out using modified Franz diffusion cell and for the optimized transdermal patch, pharmacokinetic studies were carried out using New Zealand male rabbits. Plasma samples were quantified using high-performance liquid chromatography.

Results: The in vitro diffusion studies revealed that formulation F3 with HPMC K4M and E RLPO had controlled release up to 28 hrs, and a maximum of $95.02 \pm 2.68 \%$ drug was released. The release kinetics followed mixed order non-Fickian diffusion. The pharmacokinetic studies of the optimized patch revealed controlled release up to 45 hrs where a 2.2 -fold increase in area under curve (AUC) and 3.8 times increase in mean residence time (MRT) were observed compared to oral route. The results were appeared to be significant at $\mathrm{p} \leq 0.05$. The variation in half-life was found to be not statistically significant when compared between oral and transdermal routes.

Conclusion: The pharmacokinetic results concluded that the matrix membrane moderated transdermal system with extended AUC and MRT can enhance the bioavailability of bosentan monohydrate by minimizing the drug-related side effects in oral route.

Keywords: Bosentan monohydrate, In vitro diffusion studies, Pharmacokinetic studies.

(C) 2017 The Authors. Published by Innovare Academic Sciences Pvt Ltd. This is an open access article under the CC BY license (http://creativecommons. org/licenses/by/4. 0/) DOI: http://dx.doi.org/10.22159/ajpcr.2017.v10i9.19282

\section{INTRODUCTION}

Bosentan monohydrate is the new generation endothelin receptor antagonist used to treat pulmonary arterial hypertension (PAH). PAH is characterized by elevations in the pulmonary arterial pressure and pulmonary vascular resistance leading to right ventricular failure and premature death. Bosentan monohydrate is an active dual endothelin- $\mathrm{A}$ and endothelin-B receptor antagonist and the first molecule of its class that was synthesized. Bosentan has been evaluated in PAH, and it has shown improvement in exercise capacity of the patient [1-3].

The oral therapy of bosentan monohydrate had drug-drug interactions including extensive hepatic metabolism and its oral bioavailability is $50 \%$; the pharmacokinetic properties have rationalized the drug for an alternative route [4]. As the drug is having short half-life of $5 \mathrm{hrs}$ and pKa of 4.2 [5] transdermal drug delivery can be a better alternative. Transdermal drug delivery had peculiar advantages compared to oral route where the drug-induced toxicity can be moderated simply by removing the patch; it can be given to unconscious and nauseating patients. Gastrointestinal irritation can be avoided and treatment can be terminated at any point of time. Once in a week patch was proved to be more beneficial for the elderly and memory loss patients [6,7].

In our previous works, matrix membrane moderated transdermal system of bosentan monohydrate was formulated and the results depicted a prolonged in vitro release up to $28 \mathrm{hrs}$. The transdermal patches formulated were found to be durable and stable at accelerated climatic conditions [8].

The present investigation aimed at carrying out the pharmacokinetic studies for matrix membrane moderated transdermal system of bosentan monohydrate using New Zealand male rabbits as a model. The pharmacokinetic studies will give the basic idea about the pharmacokinetics of the modified dosage form by comparing with the oral route [9]. This can be used in designing of dosage regimen based upon half-life and mean residence time (MRT) of drug in the body.

\section{MATERIALS AND METHODS}

\section{Materials}

Bosentan monohydrate was gift sample received from MSN Laboratories, India. Hdroxypropyl methylcellulose (HPMC), hydroxypropyl methylcellulose (HPMC K4M) was gift sample received from Colorcon Asia Limited, and E RLPO were gift samples received from Zhaveri Pharma Chemicals, Mumbai. Dimethyl sulfoxide (DMSO), dichloromethane (DCM), high-performance liquid chromatography (HPLC) grade acetonitrile, methanol and water were purchased from SD Fine Chemicals, Mumbai.

\section{Methods}

The matrix membrane system consists of two layers. Where the primary layer is the drug reservoir layer and the secondary layer is the rate-controlling membrane.

\section{Formulation of drug reservoir layer}

The drug reservoir layer was formulated using a simple film-forming agent HPMC. A volume of $200 \mathrm{mg}$ of HPMC was added to the solvent system of $10 \mathrm{ml}$ (DCM:methanol 1:1) and kept for stirring for an hour. Bosentan monohydrate $(60 \mathrm{mg}$ ) along with plasticizer propylene glycol $(1.2 \mathrm{ml})$ were added and stirred for another 30 minutes. The dispersion was then poured into a mold of $4 \mathrm{~cm} \times 4 \mathrm{~cm}^{2}$ and then kept for drying by covering with inverted funnel.

\section{Formulation of rate-controlling membrane}

Rate-controlling membranes were formulated using film-forming agent HPMC K4M and rate-controlling polymer E RLPO. HPMCK4M 
and E RLPO were added to the $10 \mathrm{ml}$ of solvent system (DCM:methanol in 1:1 ratio) and kept for stirring for $1 \mathrm{hr}$. Plasticizer propylene glycol $20 \%$ of polymer concentration was added and stirring was continued for another 30 minutes. About 5\% DMSO was added as penetration enhancer and stirred for another 15 minutes (Table 1). The dispersion was then poured into a mold and closed with inverted funnel for uniform drying. After 24 hrs, the dried membranes were collected and stored in a desiccator [10].

\section{Drug content}

The drug content studies were carried out using ultraviolet (UV)visible spectrophotometer at $272 \mathrm{~nm}$. The formulation was added to phosphate buffer saline (PBS) ( $\mathrm{pH}, 7.4)$ and kept for stirring for 24 hrs. The solution was then filtered and analyzed by making required dilutions

\section{In vitro diffusion studies}

Modified Franz diffusion cell was used for in vitro diffusion studies using PBS saline as media in receiver compartment [11]. The donor compartment contains transdermal system placed on dialysis membrane-150. The entire system was kept on magnetic stirrer at $50 \mathrm{rpm}$. A sample of $3 \mathrm{ml}$ was collected at regular intervals of time and sink conditions were maintained. Samples were analyzed using UV-visible spectrophotometer at $272 \mathrm{~nm}$.

Estimation of bosentan monohydrate in rabbit plasma by reversephase-HPLC

Chromatography was performed with Waters2695 HPLC provided with high-speed autosampler, column oven, degasser, and 2996 PDA detector with dual wavelength UV-visible detector operated at $273 \mathrm{~nm}$ with class Empower-2 software. ODS (C18 $250 \times 4.6,5 \mu \mathrm{L})$ analytical column was used. Mobile phase used was $0.1 \%$ orthophosphoric acid and acetonitrile in the ratio of $20: 80 \mathrm{v} / \mathrm{v} \%$ and the $\mathrm{pH}$ was adjusted to 4.6 by using triethanolamine. Retention time for bosentan monohydrate was found to be 3.6 minutes and for etodolac (internal standard) retention time was found to be at 4.1 minutes.

\section{Extraction procedure of bosentan monohydrate in plasma}

$250 \mu \mathrm{l}$ of plasma, $50 \mu \mathrm{l}$ of internal standard and $10 \mathrm{ml}$ of bosentan monohydrate were taken in a centrifuging tube with teflon-lined cap and $2 \mathrm{ml}$ of acetonitrile was added and cyclomixing was done for 15 minutes; then vertexed for 2 minutes to extract the drug into organic layer and finally centrifuged for 3 minutes at $3200 \mathrm{rpm}$ speed. After centrifugation $10 \mu \mathrm{l}$ of organic layer was directly injected into HPLC at a flow rate of $1.0 \mathrm{ml} / \mathrm{min}$.

\section{Pharmacokinetic studies}

Studies were conducted according to Ethics Committee guidelines (CPCSEA Registration No.:1677/PO/Re/S/2012/CPCSEA). Pharmacokinetic studies for the optimized formulation were carried out using male New Zealand rabbits of weight 1.3-1.5 kg. Animals were kept under stabilized condition, provided with standard food, and kept for fasting for 24 hrs before commencing the study. Rabbits were divided into four groups ( $n=5)$ : Group-I served as control group, Group I received vehicle used to make the drug suspension, for Group-III, bosentan monohydrate was given by oral route $(11 \mathrm{mg} / \mathrm{kg})$, and for Group-IV, formulated matrix membrane moderated transdermal patch of bosentan monohydrate was adhered to the skin. Hair on the sides of the vertebral column of the rabbit was removed and the transdermal patch was adhered with the help of a surgical adhesive tape. Blood sample of $1 \mathrm{ml}$ was withdrawn from left marginal ear vein at time intervals of $0,15,30$ minutes, 1, 2, 4, 8, 12, 20 and $24 \mathrm{hrs}$ for oral and 0,30 minutes, 1, 2, 4, 6, 10, 15, 20, 25, 30, 35, 40, 45, 50 and $55 \mathrm{hrs}$ for transdermal patch. The syringe used to draw blood was heparinized before using and plasma was separated immediately and stored in heparinized eppendrof and frozen at $-20^{\circ} \mathrm{C}$ till analyzed further to estimate in vivo parameters.

\section{Pharmacokinetic analysis}

Pharmacokinetic parameters were estimated from mean plasma concentration versus time graph. Pharmacokinetic parameters such as $\mathrm{C}_{\text {max }}, \mathrm{T}_{\text {max }}$, half-life $\left(\mathrm{t}_{1 / 2}\right)$, area under curve (AUC) and MRT were calculated using PKsolver an inbuilt program in Microsoft Excel 2010. Extravascular two compartment analysis was followed for transdermal patch [12] and one compartment for oral route.

\section{Statistical analysis}

All the results were done in triplicate and represented as mean \pm standard deviation. Statistical analysis like Student's t-test was performed using Microsoft Excel 2010. Significant difference was considered at $\mathrm{p} \leq 0.05$

\section{RESULTS AND DISCUSSION}

The formulated matrix membrane moderated transdermal systems were found to have excellent pharmacotechnical properties and are viable to skin and the results were reported in our previous studies [8]. The drug content in all the transdermal patches was found to be in between $99.14 \pm 0.46$ and $99.73 \pm 0.28 \%$.

The in vitro cumulative drug release data revealed that the drug release followed controlled release pattern (Fig. 1). In case of F1, by the end of $14 \mathrm{hrs} 95 \%$ of drug release was observed, by further increasing the concentration of HPMC K4M; no significant variation in the drug release pattern was observed. In case of F3, by the addition of E RLPO, maximum of $95.02 \pm 2.68 \%$ of drug release was observed by the end of $28 \mathrm{hrs}$ with a significant variation from F1 and F2 $(\mathrm{p}<0.05)$. Further increasing the concentration of E RLPO in F4 the release rate

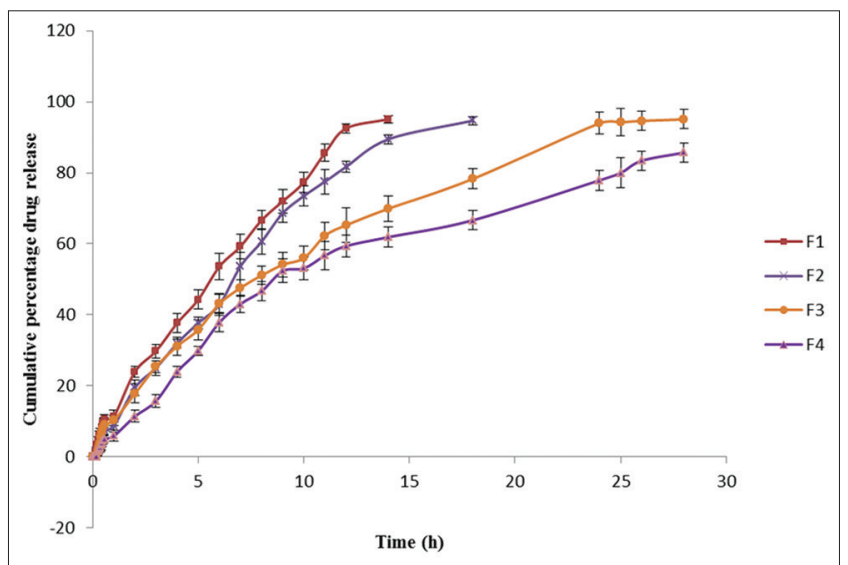

Fig. 1: Cumulative percentage in vitro release profile of bosentan monohydrate through hydroxypropyl methylcellulose $\mathrm{K} 4 \mathrm{M}$ rate-controlling membrane in phosphate buffer saline (mean \pm standard deviation, $n=3$ )

Table 1: Rate-controlling membrane by HPMC K4M

\begin{tabular}{llllll}
\hline Formulation & HPMC K4M (\%) & E RLPO (\%) & *Propylene glycol (\%) & *DMSO (\%) & DCM:Methanol (1:1) \\
\hline F1 & 1 & - & 20 & 5 & $10 \mathrm{ml}$ \\
F2 & 1.5 & - & 20 & 5 & $10 \mathrm{ml}$ \\
F3 & 1 & 0.4 & 20 & 5 & $10 \mathrm{ml}$ \\
F4 & 1 & 0.5 & 20 & 5 & $10 \mathrm{ml}$ \\
\hline
\end{tabular}

*Quantities were taken in percentage weight of polymer. HPMC: Hydroxypropyl methylcellulose, DMSO: Dimethyl sulfoxide, DCM: Dichloromethane 
Table 2: Pharmacokinetic parameters obtained after oral and transdermal administration of bosentan monohydrate (F3) (Mean \pm SD, $n=5$ )

\begin{tabular}{|c|c|c|}
\hline $\begin{array}{l}\text { Pharmacokinetic } \\
\text { parameters }\end{array}$ & Oral & $\begin{array}{l}\text { Transdermal } \\
\text { route }\end{array}$ \\
\hline $\mathrm{C}_{\max }(\mu \mathrm{g} / \mathrm{ml})$ & $1.36 \pm 0.106$ & $0.77 \pm 0.013$ \\
\hline $\mathrm{T}_{\max }^{\max }(\mathrm{h})$ & $2 \pm 0.221$ & $25 \pm 0.651^{*}$ \\
\hline Elimination rate constant $\left(\mathrm{k}_{\mathrm{e}}\right)$ & $0.151 \pm 0.012$ & $0.125 \pm 0.064$ \\
\hline Half-life (h) & $4.6 \pm 0.402$ & $5.53 \pm 1.110$ \\
\hline $\operatorname{AUC}_{(0-\infty)}(\mu \mathrm{g} / \mathrm{ml} / \mathrm{h})$ & $9.644 \pm 5.621$ & $21.752 \pm 6.216^{*}$ \\
\hline $\operatorname{AUMC}\left(\mu \mathrm{g} / \mathrm{ml} / \mathrm{h}^{2}\right)$ & $70.365 \pm 3.471$ & $624.647 \pm 5.612^{*}$ \\
\hline MRT (h) & $7.39 \pm 1.457$ & $28.71 \pm 1.548^{*}$ \\
\hline
\end{tabular}

*Statistical significant difference at $\mathrm{p} \leq 0.05$. AUC: Area under the curve, MRT: Mean residence time, AUMC: Area under the moment curve, SD: Standard deviation

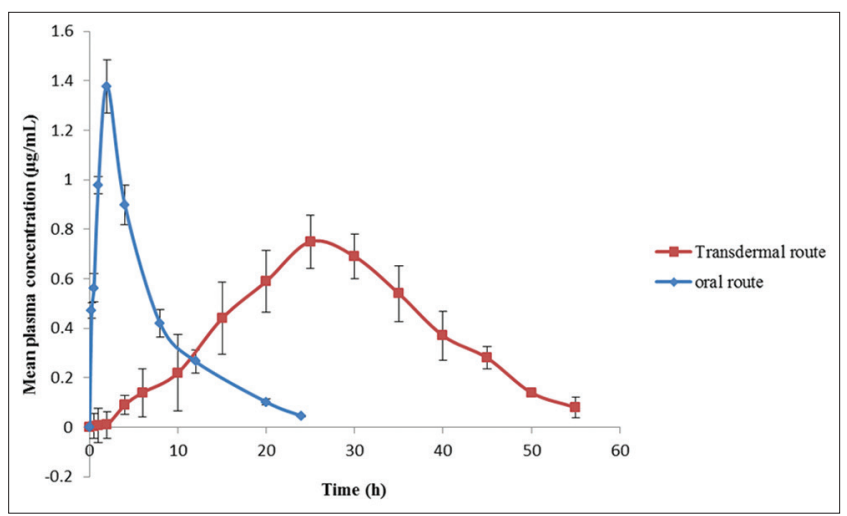

Fig. 2: Mean plasma concentration versus time profile of oral route and transdermal route of bosentan monohydrate in New

Zealand male rabbits (mean \pm standard deviation, $n=5$ )

was delayed and by the end of 28 hrs only $85 \%$ of drug release was observed

The controlled release was mainly achieved by two mechanisms, i.e., by formation of matrix by E RLPO [13] polymer swelling and polymer chain relaxation by HPMC K4M. Polymer swelling will increase the diffusion path length of the drug and this will increase accordingly with the hydrophilic polymer concentration [14]. The drug release followed mixed order non-Fickian diffusion mechanism. Based on the interpretation of above results formulation F3 was optimized for further pharmacokinetic studies as there was $95.04 \pm 2.68 \%$ of release by $24 \mathrm{hrs}$.

\section{Pharmacokinetic studies}

Pharmacokinetic modeling will give quantitative information regarding the plasma kinetic profile of drug which can be used simultaneously in pharmacodynamics modeling of the newly designed dosage form. Pharmacokinetic studies of orally administered and matrix membranecontrolled transdermal system of bosentan monohydrate were estimated from mean plasma concentration versus time profile graph (Fig. 2)

The $\mathrm{C}_{\max }$ value in oral route was found to be $1.36 \pm 0.106 \mu \mathrm{g} / \mathrm{ml}$ at $\mathrm{T}_{\max } 2 \pm 0.221 \mathrm{hrs}$ whereas in transdermal route, the $\mathrm{C}_{\max }$ value was $0.77 \pm 0.013 \mu \mathrm{g} / \mathrm{ml}$ at $\mathrm{T}_{\max } 25 \pm 0.651 \mathrm{hrs}$. In the oral route the high $\mathrm{C}_{\max }$ and low $\mathrm{T}_{\max }$ values were due to rapid absorption of the drug whereas in case of transdermal route, the decrease in $\mathrm{C}_{\max }$ and increase in $\mathrm{T}_{\max }$ were observed which is due to the formulation factor and barrier properties of the skin. The elimination half-life was found to be $4.6 \pm 0.402 \mathrm{hrs}$ in oral route whereas in transdermal it was found to be $5.53 \pm 1.114 \mathrm{hrs}$. No significant difference in half-life of the drug molecule was observed when compared to oral route. The AUC value in case of oral route was
$9.644 \pm 5.621 \mu \mathrm{g} / \mathrm{ml} / \mathrm{h}$ whereas in case of transdermal delivery AUC was found to be $21.752 \pm 6.216 \mu \mathrm{g} / \mathrm{ml} / \mathrm{h}$. The MRT values were found to be $7.39 \pm 1.457 \mathrm{hrs}$ for oral and $28.71 \pm 1.548 \mathrm{hrs}$ for transdermal route (Table 2). Statistically significant difference was found ( $\mathrm{p} \leq 0.05)$. Huge increase in AUC values by 2.25 times was observed when compared to oral route. The increase of MRT values by 3.8 times in transdermal system indicates the presence of drug for longer duration in the systemic circulation. Controlled delivery of drug into the systemic circulation and the reservoir effect after removal of the patch up to $5 \mathrm{hrs}$ were observed in the transdermal system. Controlled delivery of drug maintains the concentration of drug for longer duration thereby enhancing the bioavailability of drug. Drug-related side effects can also be minimized by avoiding the hepatic first-pass metabolism. Extravascular two compartmental analysis for transdermal route and one compartmental analysis for oral route were found to be best fit based on the regression values.

\section{CONCLUSIONS}

The pharmacokinetic studies concluded that the matrix membrane moderated transdermal patch of bosentan monohydrate can enhance the bioavailability. Extended AUC and MRT in transdermal route compared to oral route have further strengthened this assumption. There is a scope for further clinical pharmacokinetics studies. The transdermal patch was proved to be beneficial compared to oral route where drug-drug interactions can be minimized and they can enhance the patient's compliance.

\section{ACKNOWLEDGMENTS}

Authors would like to thank DST-CURIE, DST-FIST for their technical support in Modern Instrumentation facilities, Institute of pharmaceutical technology, SPMVV, for providing the advanced laboratory facilities. The research work was financially supported by UGC-BSR-RFSMS (Ref no. F. 7-346/2011)

\section{REFERENCES}

1. O'Callaghan DS, Savale L, Montani D, Jaïs X, Sitbon O, Simonneau G, et al. Treatment of pulmonary arterial hypertension with targeted therapies. Nat Rev Cardiol 2011;8(9):526-38.

2. Humbert M, Barst RJ, Robbins IM, Channick RN, Galiè N, Boonstra A, et al. Combination of bosentan with epoprostenol in pulmonary arterial hypertension: BREATHE-2. Eur Respir J 2004;24(3):353-9.

3. Galiè N, Torbicki A, Barst R, Dartevelle P, Haworth S, Higenbottam T, et al. Guidelines on diagnosis and treatment of pulmonary arterial hypertension. The task force on diagnosis and treatment of pulmonary arterial hypertension of the European society of cardiology. Eur Heart J 2004;25(24):2243-78.

4. Opitz CF, Ewert R, Kirch W, Pittrow D. Inhibition of endothelin receptors in the treatment of pulmonary arterial hypertension: Does selectivity matter? Eur Heart J 2008;29(16):1936-48.

5. New Zealand Data Sheet Pms Bosentan; 2012. Available from: http:// www.medsafe.govt.nz/profs/datasheet/p/pmsbosentantab.pdf

6. Guy RH, Hadgraft J. Selection of drug candidates for transdermal drug delivery. In: Transdermal Drug Delivery. New York: Marcel Dekker; 1989. p. $59-83$

7. Brown MB, Martin GP, Jones SA, Akomeah FK. Dermal and transdermal drug delivery systems: Current and future prospects. Drug Deliv 2006;13(3):175-87.

8. Revathi M, Indira MY. Formulation and evaluation of matrix membrane moderated transdermal patches of bosentan monohydrate. Int J Sci Eng Res 2015;6(10):746-53.

9. Seema A, Nida A, Shivsankar B. Transdermal delivery a preclinical and clinical perspective of drugs delivered via patches. Int J Pharm Pharm Sci 2014;6(5):26-38

10. Kevin CG, Anil JS, Pratik HS. Formulation and in-vitro characterization of monolithic matrix transdermal systems using Hpmc/Eudragit s 100 polymer blends. Int J Pharm Pharm Sci 2009;1(1):108-20.

11. Paranjyothy KL, Thampi PP. Development of transdermal patches of verapamil hydrochloride using carboxymethyl guar gum as a monolithic polymeric matrix and their in vitro release studies. Indian J Pharm Sci 1997:52:49-54.

12. Anissimov YG, Roberts MS. Modelling dermal drug distribution after 
topical application in human. Pharm Res 2011;28(9):2119-29.

13. Prasad Verma PR, Chandak AR. Development of matrix controlled transdermal delivery systems of pentazocine: In vitro/in vivo performance. Acta Pharm 2009;59:171-86.
14. Ubaidulla U, Reddy MV, Ruckmani K, Ahmad FJ, Khar RK. Transdermal therapeutic system of carvedilol: Effect of hydrophilic and hydrophobic matrix on in vitro and in vivo characteristics. AAPS Pharm Sci Tech 2007;8(1):2. 